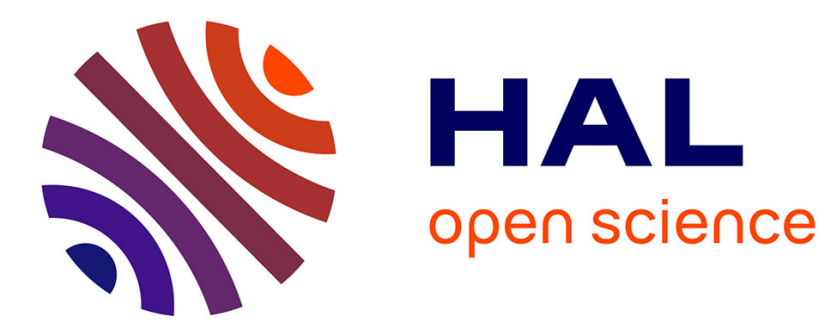

\title{
Subregional inversion of North African dust sources
}

Jerónimo Escribano, Olivier Boucher, Frédéric Chevallier, Nicolás Huneeus

\section{To cite this version:}

Jerónimo Escribano, Olivier Boucher, Frédéric Chevallier, Nicolás Huneeus. Subregional inversion of North African dust sources. Journal of Geophysical Research: Atmospheres, 2016, 121 (14), pp.85498566 10.1002/2016JD025020 . hal-01366496

\section{HAL Id: hal-01366496 https://hal.sorbonne-universite.fr/hal-01366496}

Submitted on 15 Sep 2016

HAL is a multi-disciplinary open access archive for the deposit and dissemination of scientific research documents, whether they are published or not. The documents may come from teaching and research institutions in France or abroad, or from public or private research centers.
L'archive ouverte pluridisciplinaire HAL, est destinée au dépôt et à la diffusion de documents scientifiques de niveau recherche, publiés ou non, émanant des établissements d'enseignement et de recherche français ou étrangers, des laboratoires publics ou privés. 


\section{Journal of Geophysical Research: Atmospheres}

\section{RESEARCH ARTICLE \\ 10.1002/2016JD025020 \\ Key Points: \\ - Satellite AOD retrievals are assimilated \\ for a 1 year period over North Africa \\ - Strengths and weaknesses of the \\ source inversion system are discussed \\ - Retrievals of fine and coarse AOD over land and ocean with reduced biases would further improve emission estimates}

Correspondence to:

J. Escribano,

jeronimo.escribano@Imd.jussieu.fr

\section{Citation:}

Escribano, J., O. Boucher, F. Chevallier, and N. Huneeus (2016), Subregional inversion of North African dust sources, J. Geophys. Res. Atmos., 121, 8549-8566, doi:10.1002/2016JD025020.

Received 1 MAR 2016 Accepted 30 JUN 2016 Accepted article online 12 JUL 2016 Published online 23 JUL 2016

\section{Subregional inversion of North African dust sources}

\author{
Jerónimo Escribano ${ }^{1}$, Olivier Boucher ${ }^{1}$, Frédéric Chevallier ${ }^{2}$, and Nicolás Huneeus ${ }^{3,4}$ \\ ${ }^{1}$ Laboratoire de Météorologie Dynamique, Université Pierre et Marie Curie/CNRS, Paris, France, ${ }^{2}$ Laboratoire des Sciences \\ du Climat et de I'Environnement, CEA, Saclay, France, ${ }^{3}$ Geophysics Department, University of Chile, Santiago, Chile, \\ ${ }^{4}$ Center for Climate and Resilience Research, Santiago, Chile
}

Abstract The emission of mineral dust aerosols in arid and semiarid regions is a complex process whose representation in atmospheric models remains crude, due to insufficient knowledge about the aerosol lifting process itself, the lack of global data on soil characteristics, and the impossibility for the models to resolve the fine-scale variability in the wind field that drives some of the dust events. As a result, there are large uncertainties in the total emission flux of mineral dust, its natural variability at various timescales, and the possible contribution from anthropogenic land use changes. This work aims for estimating dust emissions and reduces their uncertainty over the Sahara desert and the Arabian Peninsula - the largest dust source region of the globe. We use a data assimilation approach to constrain dust emission fluxes at a monthly resolution for 18 subregions. The Moderate Resolution Imaging Spectroradiometer satellite-derived aerosol optical depth is assimilated in a regional configuration of a general circulation model coupled to an aerosol model. We describe this data assimilation system and apply it for 1 year, resulting in a total mineral dust emissions flux estimate of $2900 \mathrm{Tg} \mathrm{yr}^{-1}$ over the Sahara desert and the Arabian Peninsula for the year 2006. The analysis field of aerosol optical depth shows an improved fit relative to independent Aerosol Robotic Network measurements as compared to the model prior field.

\section{Introduction}

The role of desert dust in the climate system has been studied intensively in the past years [Knippertz and Stuut, 2014, and references therein]. It has been shown that atmospheric mineral dust has a number of impacts on a wide range of components and scales in the Earth system. Saharan dust has a fertilization effect in the Atlantic Ocean and the Mediterranean Sea because of its iron content that can become biologically available to phytoplankton when dust is deposited at the ocean surface [Jickells et al., 2005; Mahowald et al., 2014]. It also brings a large fraction of the aeolian input of phosphorus (a limiting nutrient) over the Amazon forest ecosystem [Koren et al., 2006; Mahowald et al., 2014]. Mineral dust has impacts on air quality and human health [Goudie, 2014]. Finally, mineral dust also interacts with radiation and clouds in the atmosphere [e.g., Haywood et al., 2005; Atkinson et al., 2013], with gas-phase species through heterogeneous chemistry [Dentener et al., 1996], and it has been hypothesized that it may influence microphysical-related processes in the cyclogenesis over the Atlantic Ocean [Bretl et al., 2015].

Despite the important and central roles of desert dust in the Earth system, the total mass of aerosol emissions is still highly uncertain [Huneeus et al., 2011]. Observations, modeling, and combined approaches have been used to narrow the uncertainty in emissions both at the global [Cakmur et al., 2006; Huneeus et al., 2012] and regional [Yumimoto et al., 2008; Huneeus et al., 2011] scales. Models continue to experience difficulties to simulate the correct seasonal cycle of dust emissions probably for a variety of reasons. First of all, the emission process is not well understood even though dust lifting models have been improved and complexified [Woodward, 2001; Zender et al., 2003; Kok, 2011]. We also lack reliable data on soil characteristics (size distribution, mineral composition, crusting effect, etc.) despite recent progress in mapping soil mineralogy [Journet et al., 2014]. Furthermore, atmospheric models do not resolve the fine-scale variability in the surface wind, and parametrizations have to be introduced to represent these effects [Zhang et al., 2016].

The amount of dust in the atmosphere can be estimated from satellite-borne passive instruments, both in the ultraviolet-visible part of the electromagnetic spectrum with, e.g., the Moderate Resolution Imaging Spectroradiometer (MODIS) [Levy et al., 2013], the Multiangle Imaging Spectroradiometer (MISR) [Kahn et al., 2009],
๑2016. American Geophysical Union. All Rights Reserved. 
and the Polarization and Anisotropy of Reflectances for Atmospheric Sciences Coupled with Observations from a Lidar (PARASOL) [Tanré et al., 2011], and in the infrared with, e.g., the Infrared Atmospheric Sounder Interferometer (IASI) [Peyridieu et al., 2013], as well as from ground-based passive instruments (e.g., Sun photometers). Active remote sensing methods can also be used in the visible part of the spectrum with either ground-based or satellite-based lidar systems. All these measurements are based on the interpretation of the interactions between dust aerosols and radiation, which introduces some uncertainty in the estimate because of uncertainties in dust morphology and particle shape, size distribution, and hence optical properties, as well as in the surface scattering properties. Several aerosol chemical and physical properties have been assessed in intensive measurement campaigns [Redelsperger et al., 2006; Washington et al., 2006; Ansmann et al., 2011; Washington et al., 2012], giving valuable information on dust aerosol emissions, transport, deposition processes, and chemical and physical properties. However, such surface or atmospheric measurements are very sparse in space and time, which limits their usefulness for constraining the regional or global cycle of mineral dust. Many studies rely on long-term series of observations (e.g., ground-based Sun photometers, ground-based lidar, and satellite-borne instruments) to constrain the dust cycle. Regrettably, these long-term observations report the amount of atmospheric dust; they cannot be directly translated into estimates of dust fluxes, and they are not enough on their own to constrain dust fluxes for large areas (such as the Sahara desert or eastern Asia). In this context, data assimilation is an attractive tool that allows combining available observations with existing modeling tools in order to estimate emissions.

Data assimilation techniques are widely used in atmospheric chemistry to improve the modeled concentrations of various chemical species [Bocquet et al., 2015] and are necessary to produce realistic forecasts [Benedetti et al., 2009]. These techniques also constitute a useful tool to constrain the atmospheric fluxes of a number of chemical species whether they are short-lived such as $\mathrm{HCHO}$ and $\mathrm{CO}$ [e.g., Fortems-Cheiney et al., 2012] or longer-lived such as $\mathrm{CO}_{2}$ [e.g., Chevallier et al., 2010] or $\mathrm{CH}_{4}$ [e.g., Bousquet et al., 2006]. Such techniques have also been used for aerosol species, assimilating surface concentration observations [e.g., Hakami et al., 2005], aerosol extinction coefficients from lidar instruments [e.g., Yumimoto et al., 2008], or aerosol optical depth [e.g., Dubovik et al., 2008; Schutgens et al., 2012; Huneeus et al., 2012; Yumimoto and Takemura, 2013]. One of the difficulties associated with aerosols is that aerosol optical depth (AOD) observations do not usually distinguish the chemical composition of the aerosol, which makes the inversion problem particularly underconstrained. For mineral dust, there is an additional difficulty in that the background emission flux needs to be computed in the model rather than prescribed from an emission inventory.

The aim of this study is to quantify the dust flux emissions over the Sahara desert and the Arabian Peninsula with sufficient temporal and spatial resolution to be able to capture the main emission features and variability over a 1 year period. For this reason our emphasis is on a regional source inversion that can take full benefit of satellite data and increased model resolution.

Section 2 presents the data assimilation system used in this work, including the meteorological model, the dust emission model, the aerosol model, and the assimilated observations. We show results of the AOD assimilation in section 3, comparing model simulations with observations and estimating dust fluxes. Results and performance of the assimilation system are discussed in section 4. We present our conclusions in section 5.

\section{Data and Methods}

\subsection{LMDz-SPLA Model}

\subsubsection{Meteorological and Aerosol Model}

We use the simplified aerosol (SPLA) model [Huneeus et al., 2009] coupled to the general circulation model of the Laboratoire de Météorologie Dynamique (LMDz) [Hourdin et al., 2013]. The LMDz is a hydrostatic model with hybrid vertical coordinate and a stretchable latitude-longitude horizontal grid. The model numerically solves the advection equations on a three-dimensional grid (the so-called "dynamics"). Subgrid-scale processes, including radiative transfer, cloud, and boundary layer processes, are parameterized as part of the "physics" part of the model. The SPLA model is an aerosol model of intermediate complexity that is fully embedded in the LMDz model; it was originally designed for data assimilation purposes but has evolved in several aspects since then. Major changes of SPLA are listed in the next paragraphs of this section, mainly associated to updates in emissions of natural aerosols and in physical processes parameterizations and also associated to changes in aerosol bin definitions (with a consistent update of sedimentation velocities and 
optical aerosol properties). The SPLA model has been used to estimate global aerosol emissions in Huneeus et al. [2012].

The following processes are included in the aerosol model for aerosols and their gaseous precursors: surface and elevated emissions, dry deposition, boundary layer mixing, transport from subgrid-scale thermals [Hourdin et al., 2015], sedimentation for coarse mode aerosols, gas-to-particle conversions, in-cloud and below-cloud scavenging, convective transport, and large-scale transport.

As stated above, we have performed major updates to the SPLA model. The number of modeled species has been increased. The model presented in Huneeus et al. [2009] had four tracers: gaseous precursors of aerosols, coarse mode sea salt (with diameters between 1 and $40 \mu \mathrm{m}$ ), fine mode aerosols, and coarse mode dust. In the present work, mineral dust aerosols are distributed in three bins that represent supercoarse dust (between 6 and $30 \mu \mathrm{m}$ of diameter), coarse mode dust (between 1 and $6 \mu \mathrm{m}$ of diameter), and fine mode dust (with diameter smaller than $1 \mu \mathrm{m}$ ). After emission, fine mode dust is included in the fine mode aerosols tracer (which also includes black carbon, particulate organic matter, and sulfate aerosols), so in practice the SPLA model has only five tracers now. Additional work has been done to update the SPLA model according to the latest developments of the LMDz model, including the parameterization of thermals in the boundary layer [Hourdin et al., 2015] and the convective transport and scavenging scheme [Pilon et al., 2015].

\subsubsection{Dust Emission Model}

Over the Sahara desert and the Arabian Peninsula, the mineral dust emissions are calculated online using a parametrization described below.

The dust production module (DPM) originally used in the CHIMERE-DUST air quality model [Menut et al., 2013] has been embedded in the SPLA model. Our implementation is based on the DPM adaptation from Hourdin et al. [2015], which calculates mineral dust emissions online and only over the Sahara desert and the Arabian Peninsula. The DPM is composed essentially of a saltation flux scheme from Marticorena and Bergametti [1995] and a sandblasting model from Alfaro and Gomes [2001]. Threshold friction velocities are estimated following Shao and Lu [2000] and corrected by a drag efficiency coefficient as in Marticorena et al. [1997]. Input soil data over the Sahara desert and the Arabian Peninsula are taken from the Laboratoire Interuniversitaire des Systèmes Atmosphériques (LISA) database (available at http://www.lisa.univ-paris12.fr/mod/data/index.php).

The DPM scheme includes a Weilbull-like wind speed distribution to represent subgrid-scale variability as explained in Hourdin et al. [2015]. The dust fluxes are calculated and summed over the bins of the discretized wind speed distribution, for each grid box and each time step of the physics of the model (set to $15 \mathrm{~min}$ ). The subgrid wind speed distribution, in its continuous form, is given by the following probability density function:

$$
p(u, k, A)=\frac{k}{A}\left(\frac{u}{A}\right)^{k-1} \exp \left[-\left(\frac{u}{A}\right)^{k}\right]
$$

where $u$ is the subgrid-scale wind speed and $(k, A)$ are parameters of the Weibull distribution. The shape parameter $k$ has been set equal to 3 as in Hourdin et al. [2015], and the $A$ parameter is calculated for each grid cell and each time step to fit the Weibull distribution expectancy with the mean wind velocity from the LMDz model: $U=A \Gamma(1+1 / k)$, where $U$ is the $10 \mathrm{~m}$ mean wind for each grid cell and $\Gamma$ the Gamma function.

For each soil type from the LISA database, the horizontal saltation flux $F_{h}$ is calculated according to Marticorena and Bergametti [1995] as

$$
F_{h}\left(D_{p}, s\right)=\frac{K \rho_{a} U^{*}(s)^{3} S_{\mathrm{rel}}\left(D_{p}, s\right)}{g}\left(1+\frac{U_{t}^{*}\left(D_{p}, s\right)}{U^{*}(s)}\right)\left(1-\frac{U_{t}^{*}\left(D_{p}, s\right)^{2}}{U^{*}(s)^{2}}\right),
$$

where $s$ is the soil type, $D_{p}$ is the soil particle diameter, $K$ is a constant value, $\rho_{a}$ is the air density, $g$ is the gravitational constant, $U^{*}$ is the friction velocity (which depends on the soil type through the saltation roughness length parameter), $U_{t}^{*}$ is the threshold friction velocity, and $S_{\text {rel }}$ is the proportion of the surface covered by particles of type $s$ with diameter $D_{p}$. In the case of $U_{t}^{*}\left(D_{p}, s\right)>U^{*}(s)$, the friction velocity threshold is not reached by the model and there are no emissions $\left(F_{h}\left(D_{p}, s\right)=0\right)$. In this work, the value of $K$ is set to its original value of 2.61 [Marticorena and Bergametti, 1995] instead of the value of 1.0 used in Hourdin et al. [2015] and in Menut et al. [2013]. 
After the saltation scheme, the sandblasting model is used to calculate the vertical dust flux assuming that it is emitted by three soil modes [Alfaro and Gomes, 2001]. For each soil type s, soil particle diameter $D_{p}$ and soil mode $i$, the vertical flux $F_{v}$ is

$$
F_{v, i}\left(D_{p}, s\right)=\frac{\pi}{6} \beta \rho_{p} \frac{p_{i}\left(D_{p}, s\right) d_{i}^{3}}{e_{i}} F_{h}\left(D_{p}, s\right),
$$

where $\beta=16,300 \mathrm{~cm} \mathrm{~s}^{-2}, \rho_{p}$ is the particle density, $d_{i}$ is the mass median diameter for the mode $i, e_{i}$ is the binding energy for the mode $i$, and $p_{i}$ is the fraction of kinetic energy for the binding energy $e_{i}$, calculated as in Alfaro and Gomes [2001]. The total dust flux for the mode $i$ is calculated by the sum of the contributions of all the soil types:

$$
F_{v, i}=\sum_{s} \int_{D_{p}^{\min }}^{D_{p}^{\max }} F_{v, i}\left(D_{p}, s\right) \mathrm{d} D_{p},
$$

where $D_{p}^{\max }$ and $D_{p}^{\min }$ are the maximum and minimum particle diameters for the soil size distribution. Finally, the vertical flux of the three modes from Alfaro and Gomes [2001] scheme is redistributed into the SPLA tracers for fine, coarse, and supercoarse mode dust.

Some of the key parameters of this scheme are the binding energy parameters, which account for the necessary energy to release particles in the sandblasting processes for each soil mode used in the scheme. The work by Sow et al. [2011] shows that these binding energy parameters should not be constant to fit in situ emission flux measurements; instead, they may depend on the strength of the dust event. Sow et al. [2011] divide the binding energy parameters by a factor 2.5 in the case of a strong dust event, and by a factor of 5 in the case of a weaker event to fit in situ emission flux measurements. We also choose to tune the binding energy parameters and divide it by a sixfold factor. This is somewhat an arbitrary choice but is partly justified by the fact that we are interested in simulating the dust flux emission for a long period (and not only for dust events).

Data assimilation systems are sensitive to biases in the observations and in the observation operator (the LMDz-SPLA model in our case). Biases can be propagated to the analysis and deteriorate the analysis performance [e.g., Dee, 2005]. The simulated AOD from the LMDz-SPLA model is systematically low over the region of focus, and the study of the source of this bias is out of the scope of this work. To avoid a bias in the observation operator and in order to have a mean simulated AOD in the range of the (satellite and ground-based) observations, we apply a tuning multiplicative factor equal to 3.25 to the coarse and supercoarse dust emissions and 0.8 to the fine mode dust emissions. The tuning factor is not the same for the three emission bins due to the known overestimation of fine mode dust emissions in the DPM relative to the coarser modes [Nabat et al., 2012].

Although our focus is over the Sahara and the Arabian Peninsula, it is likely that dust emitted outside this region can be advected to our region of interest. To address this, dust emissions outside the Sahara and the Arabian Peninsula are calculated off-line from ERA-Interim $10 \mathrm{~m}$ wind speed as in Huneeus et al. [2013].

\subsubsection{Other Emissions}

Emissions of remaining aerosol species and gaseous precursors, except dimethyl sulfide (DMS), are similar to those used in Huneeus et al. [2013]. The climatology of ocean near-surface dimethyl sulfide (DMS) concentration has been updated with the work of Lana et al. [2011], and the DMS emission flux is calculated (like in Huneeus et al. [2013]) with the parameterization by Nightingale et al. [2000]. Anthropogenic emissions for the year 2000 from Lamarque et al. [2010] have been used. Daily biomass burning (BB) emissions fluxes are taken from the GFED 3.1 inventory [van der Werf et al., 2010]. In the region of interest, almost all BB emissions fluxes are located south to the Saharan desert, and they have a strong annual cycle with BB emissions being maximum between November and February.

\subsection{Observations}

Total AOD at $550 \mathrm{~nm}$ is assimilated from satellite retrievals, while ground-based measurements are used only for validation purposes. We use total $550 \mathrm{~nm}$ AOD retrievals from the daily Level 3 Merged Dark Target/Deep Blue [Levy et al., 2013] product from the Moderate Resolution Imaging Spectroradiometer (MODIS) instrument, on board the polar Sun-synchronous orbit satellite Aqua.

For validation purpose, we use daily $500 \mathrm{~nm}$ AOD Level 2 retrievals from the Aerosol Robotic Network (AERONET) Sun photometers [Holben et al., 1998], without any postprocessing or preprocessing. For satellite data only, we regrid the AOD retrievals into the model grid. 


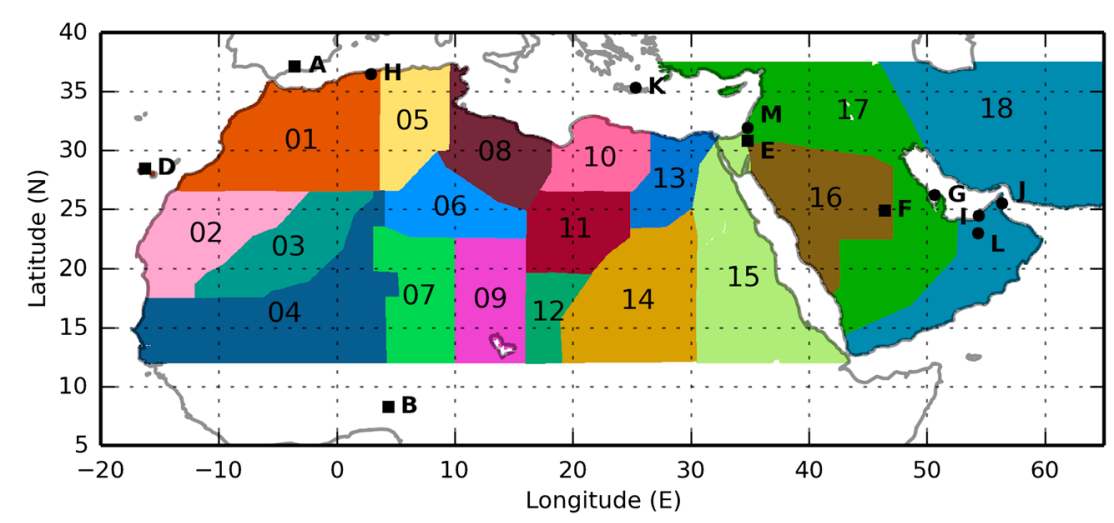

Figure 1. Numbered subregions for fine dust and coarse and supercoarse dust correction factors (composing the control vector elements). AERONET sites used in this study (Figure 5 and Table 1) are shown with letters A-F (squares). Remaining AERONET sites (circles) of Table 1 are shown with letters G-M. The AERONET sites are Granada (A), llorin (B), La Parguera (C, not shown in this figure), Santa Cruz Tenerife (D), Sede Boker (E), Solar Village (F), Bahrain (G), Blida (H), Dhabi (I), Dhadnah (J), Forth Crete (K), Hamim (L), and Nes Ziona (M).

\subsection{Data Assimilation System}

Our objective is to find the best emission estimate, combining information from models and observations. The optimality of the assimilated emissions is formulated in terms of the minimization, over the control vector $\mathbf{x}$, of the following cost function:

$$
J(\mathbf{x})=\frac{1}{2}\left(\mathbf{x}-\mathbf{x}^{b}\right)^{T} \mathbf{B}^{-1}\left(\mathbf{x}-\mathbf{x}^{b}\right)+\frac{1}{2}\left(\mathbf{y}^{o}-H(\mathbf{x})\right)^{T} \mathbf{R}^{-1}\left(\mathbf{y}^{o}-H(\mathbf{x})\right),
$$

where $\mathbf{x}^{b}$ is the background (or prior) control vector, $\mathbf{y}^{o}$ is the observation vector, $H$ is the observation operator, $\mathbf{B}$ is the covariance matrix of the background errors, and $\mathbf{R}$ is the covariance matrix of the observations errors. The minimum of the cost function is achieved for the "analysis"; it is denoted $\mathbf{x}^{a}$ and calculated in this work through the use of a constrained minimization algorithm, given the constraints over the control vector, as explained in the next sections.

\subsubsection{Control Vector}

The control vector $\mathbf{x}$ is composed of multiplicative correction factors of the model emissions. We split the spatial domain of interest in a number of "subregions," and the temporal domain in a number of "subperiods." We also define a number of emission "categories," which are related to the type of aerosol (or aerosol precursor) included in the emission scheme of the model.

We assume constant correction factors over each subregion, subperiod, and emission category. The number of subregions and subperiods depend on the category of emission. Following the approach applied in Huneeus et al. [2013], we define six emission categories: fine desert dust, coarse and supercoarse desert dust, biomass burning emissions, fine mode sea salt, coarse mode sea salt, and anthropogenic $\mathrm{SO}_{2}$ and fossil fuel emissions. Only one region is considered for fine sea salt, coarse sea salt, anthropogenic $\mathrm{SO}_{2}$, and fossil fuel emissions, which covers the entire globe. The seasonality of sea salt emissions is assumed to be correct in the model, and only one time period (of 1 year) is used for sea salt. For biomass burning emissions, two subregions are constructed based on the land cover class map of Kaiser et al. [2012], one for grassland-like (including savannah) land cover and a second one for forest-like land cover. The correction factors have a monthly resolution for biomass burning.

We define 18 dust subregions over the area of interest (Figure 1) as we expect that most of the AOD observed in the assimilation region (Figure 2) is due to aerosol emitted over the Sahara desert, the Arabian Peninsula, and over the Atlantic Ocean. However, a nineteenth dust subregion is also defined for the rest of the globe, because its emissions can also occasionally influence the AOD in the region of interest. The subregions are the same for the three categories of dust. Their number is a trade-off between the expected spatial resolution of the analysis and the computational cost of our inversion system. The maximum possible number of subregions would correspond to the number of model grid boxes. The main idea is to construct subregions that are as large as possible and also homogeneous, so as to get an affordable quantity of subregions consistent with the information content of the observations. 


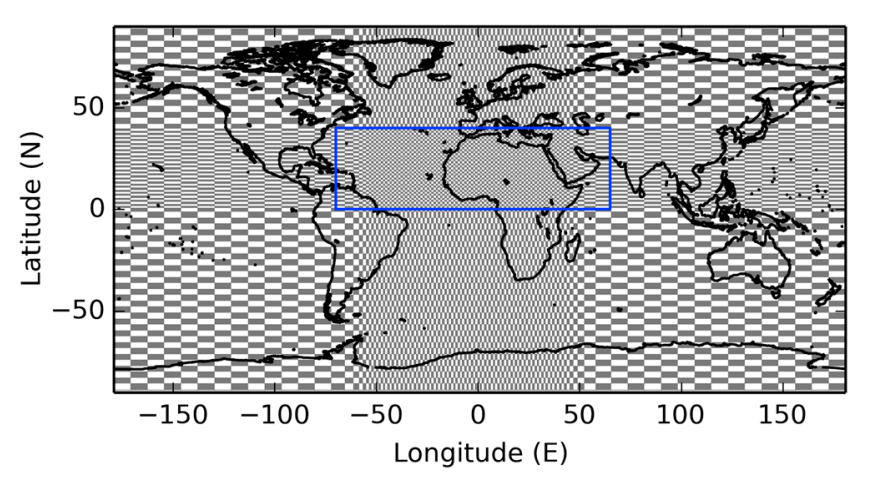

Figure 2. Representation of the LMDz grid. The blue rectangle depicts the assimilation region as described in the text.

We define the dust subregions in the following way: first, the distribution of the dust-emitted flux is calculated for a long period (1 year in our case) at an hourly output resolution. We then compute the temporal correlation of the emission flux in each grid box with the other grid boxes. With this calculation, we obtain a correlation map for each grid box in the region of interest (not shown). The idea is then to group the most similar grid boxes into subregions, so that the temporal emission patterns of grid boxes within a given subregion are similar. For this purpose, two clustering methods have been used: $\mathrm{K}$ means and Gaussian Mixture Model (implemented by Pedregosa et al. [2011]). These two methods allow creating a spatial partition of the region of interest, but they only use information from the model dust fluxes. The final step is to manually modify the subregions created by the clustering analysis by including information on the dust source that is available in the literature [Schepanski et al., 2007; Ginoux et al., 2012] and to join or split the subregions in order to (i) keep a known dust source location into a single subregion and (ii) keep well-known dust sources as separate subregions. This last step in the subregion construction has an arbitrary or subjective component but is a way to include key information in the construction process.

Alternatively, it would be possible to define the subregions based on the AOD retrievals within the inversion process itself [Bocquet et al., 2011]. However, given the associated substantial increase of the computational burden, we prefer to define the subregions using model information only.

In terms of temporal resolution, our inversion system allows for a different number of subperiods for each category of correction factors in the control vector. In this work, coarse sea salt and fine sea salt are defined with one element per year, which means that the correction factors for fine and coarse sea salt emissions have a yearly resolution. For the rest of the elements in the control vector, we set a monthly resolution, which means that we have one element in the control vector per category of emissions, subregion, and month. In summary, for a 1 year assimilation, the number of elements in the control vector is $19 \times 12$ for fine dust, $19 \times 12$ for coarse and supercoarse mode dust (lumped together), $2 \times 12$ for biomass burning, $1 \times 12$ for anthropogenic and fossil fuel emissions, 1 for fine sea salt, and 1 for coarse sea salt, which gives a total of 494 elements for the control vector.

\subsubsection{Observation Operator and Minimization Procedure}

The $550 \mathrm{~nm}$ AOD estimation by the LMDz-SPLA model from the emissions is used as the observation operator. To compare the model output with the MODIS/Aqua retrievals, the model AOD is sampled at 13:30 equatorial local time to match the satellite overpass time. We discard all the pixels with an AOD difference larger than 1 with regard to the prior simulation because large differences between the prior simulation and the observations can deteriorate the quality of the analysis [Lorenc and Hammon, 1988]. The number of observations discarded by this filter is less than the $2 \%$ of the total number of observations. Comparison with AERONET is done using the model daily mean AOD at the model grid box level. We extrapolate the simulated $550 \mathrm{~nm}$ AOD into a $500 \mathrm{~nm}$ AOD using the 550-670 Ångström coefficient that is also computed in the model. As neither the linear tangent nor the adjoint model has been coded for the new version of LMDz-SPLA model, the minimization of equation (5) is done only using the forward model. In order to minimize equation (5), the observation operator is approximated by

$$
H(\mathbf{x})=H\left(\mathbf{x}^{b}\right)+\mathbf{H}\left(\mathbf{x}-\mathbf{x}^{b}\right)
$$


where $\mathbf{H}$ is the Jacobian of the nonlinear observation operator $H$, evaluated at the $\mathbf{x}^{b}$ point, and calculated trough finite differences. Perturbations are chosen equal to one, and they are within the expected order of magnitude of correction factor differences between the analysis and the prior.

In principle it is necessary to perform a number of forward simulations (at least) equal to the number of elements in the control vector plus one (for the background or prior simulation), to fully construct the $\mathbf{H}$ matrix. With the aim of saving computing time, only the background simulation is made for the whole 1 year period. To compute the AOD due to perturbations in the elements of the control vector (and to reduce the computing time), we take advantage of the relative short residence time of atmospheric aerosols and we assume that the effect of the perturbation in emission is negligible beyond 15 days after the end of the perturbation for each subperiod and, by definition, is equal to zero for all the days before the emission perturbation is perturbed. Under this assumption, each simulation associated with a 1 month subperiod is calculated by simulating only one and a half month instead of a whole year, thus saving a considerable amount of computing time.

With the linear approximation of $H$, the cost function is a quadratic function, and the solution space is bounded by the constraint of the nonnegativeness of the control vector that we choose to impose. As the solution space of the optimization problem is bounded, we cannot use the standard linear algebra solution from the unconstrained problem. Instead, we directly minimize the cost function using an appropriate numerical solver, which takes advantage of the convexity of the optimization problem. The minimization is performed for all the elements of the control vector simultaneously.

We use the inverse of the Hessian of the cost function (evaluated at the analysis point) to estimate the analysis error covariance matrix $\mathbf{A}$. In an unconstrained framework, the $\mathbf{A}$ matrix is estimated as

$$
\mathbf{A}=\left(\mathbf{H}^{T} \mathbf{R}^{-1} \mathbf{H}+\mathbf{B}^{-1}\right)^{-1} .
$$

In the constrained case, the computation of $\mathbf{A}$ is the same as in equation (7), because the bounds do not change the Hessian of the cost function in the solution space. Standard deviations of analysis errors are estimated as the square root of the diagonal terms of $\mathbf{A}$.

\subsection{3. $B$ and $R$ Matrices}

In principle we use variances of background (B) and observation (R) errors from Huneeus et al. [2013]. Standard deviations of the observational errors are set to 0.2 for MODIS AOD over land and 0.1 for MODIS AOD over ocean in R. Standard deviation of the model error is set to 0.02 in $\mathbf{R}$. Errors associated with dust bin discretization and other model equation discretizations are implicitly embedded in the model error in the $\mathbf{R}$ matrix. Huneeus et al. [2012] show that 0.02 is an appropriate value for the model error of the LMDz-SPLA AOD observation operator. Standard deviations of the background errors are set as 3.0 for dust emissions (coarse and supercoarse modes lumped together and fine mode), 1.3 for biomass burning emissions, 2.0 for sea salt emissions (fine and coarse), and 0.18 for anthropogenic and fossil fuel emissions in B. Unlike Huneeus et al. [2013], we have included two types of nondiagonal terms in the $\mathbf{B}$ matrix. The first accounts for the correlation between the errors in the dust emission of the two dust categories in a same subperiod. We have fixed this through a correlation coefficient of 0.6 . A second correlation has been introduced between different subperiods for the same subregion and category of emission. We assume a Gaussian correlation [Pannekoucke et al., $2008]$, and we use a timescale $L$ of 20 days so that

$$
\rho_{L}=\exp \left(-\frac{(\Delta T)^{2}}{2 L^{2}}\right)
$$

where $\Delta T$ is the time between the two subperiods associated to the pair of elements in the control vector, in the same units as the timescale $L$.

The matrices $\mathbf{B}$ and $\mathbf{R}$ have been inflated to satisfy two of the a posteriori diagnostics presented in Desroziers et al. [2005] for the trace of the matrices, and specifically the diagnostic related to the observational errors and the one related to the analysis errors. In other words, we have calculated two scalars $\alpha_{\mathbf{B}}$ and $\alpha_{\mathbf{R}}$ such that

$$
\begin{gathered}
\operatorname{Tr}\left(\mathbf{d}_{a}^{o}\left(\mathbf{d}_{b}^{o}\right)^{T}\right)=\operatorname{Tr}\left(\mathbf{R}_{\alpha_{\mathrm{R}}}\right), \\
\operatorname{Tr}\left(\mathbf{d}_{b}^{a}\left(\mathbf{d}_{a}^{o}\right)^{T}\right)=\operatorname{Tr}\left(\mathbf{H A}_{\alpha_{\mathbf{B}}, \alpha_{\mathrm{R}}} \mathbf{H}^{T}\right),
\end{gathered}
$$


where $\operatorname{Tr}$ is the trace of the matrix and

$$
\begin{aligned}
\mathbf{d}_{b}^{o} & =\mathbf{y}^{o}-H\left(\mathbf{x}^{b}\right), \\
\mathbf{d}_{b}^{a} & =H\left(\mathbf{x}^{a}\right)-H\left(\mathbf{x}^{b}\right), \\
\mathbf{d}_{a}^{o} & =\mathbf{y}^{o}-H\left(\mathbf{x}^{a}\right), \\
\mathbf{R}_{\alpha_{\mathbf{R}}} & =\alpha_{\mathbf{R}} \mathbf{R}, \\
\mathbf{A}_{\alpha_{\mathbf{B}}, \alpha_{\mathbf{R}}} & =\left(\mathbf{H}^{T}\left(\alpha_{\mathbf{R}} \mathbf{R}\right)^{-1} \mathbf{H}+\left(\alpha_{\mathbf{B}} \mathbf{B}\right)^{-1}\right)^{-1}, \\
H(\mathbf{x}) & =H\left(\mathbf{x}^{b}\right)+\mathbf{H}\left(\mathbf{x}-\mathbf{x}^{b}\right),
\end{aligned}
$$

and

$$
\mathbf{x}^{a}=\operatorname{argmin}_{\mathbf{x} \geq 0}\left\{\frac{1}{2}\left(\mathbf{x}-\mathbf{x}^{b}\right)^{T} \mathbf{B}_{\alpha_{\mathbf{B}}}^{-1}\left(\mathbf{x}-\mathbf{x}^{b}\right)+\frac{1}{2}\left(\mathbf{y}^{o}-H(\mathbf{x})\right)^{T} \mathbf{R}_{\alpha_{\mathbf{R}}}^{-1}\left(\mathbf{y}^{o}-H(\mathbf{x})\right)\right\} .
$$

After calculations, the inflation factor for the $\mathbf{R}$ matrix $\left(\alpha_{\mathbf{R}}\right)$ is equal to 1.09 and the inflation factor for the $\mathbf{B}$ matrix $\left(\alpha_{\mathbf{B}}\right)$ is 4.08. Consequently, we define $\mathbf{B}^{\prime}=4.08 \times \mathbf{B}$ and $\mathbf{R}^{\prime}=1.09 \times \mathbf{R}$. The factor $\alpha_{\mathbf{B}}=4.08$ may account for missing covariances of the background errors. The factor is calculated in the observational space using diagnostics of the analysis; thus, the interpretation of the factor $\alpha_{\mathrm{B}}$ in the parameter space is not direct. However, this factor leads to a prior uncertainty of the dust fluxes in the expected range (see section 3.5).

\subsection{Experimental Configuration}

We focus this study on the Sahara desert and Arabian Peninsula region, and we take advantage of the zoom capability of the atmospheric model to choose a model grid with a horizontal resolution close to $1^{\circ}$ by $1^{\circ}$ over the Sahara desert (Figure 2). The model grid has an average resolution of $1^{\circ}$ in latitude and $1.4^{\circ}$ in longitude in the latitude-longitude box defined by the corners $\left[0^{\circ} \mathrm{N}, 70^{\circ} \mathrm{W}\right]$ and $\left[40^{\circ} \mathrm{N}, 70^{\circ} \mathrm{E}\right]$. This grid is a compromise between the computing cost of the system and our computing capabilities; it is also selected to reduce the impact of the regridding process of the dust emission model input data, which is provided at the $1^{\circ}$ by $1^{\circ}$ resolution, into the atmospheric model grid. The global atmospheric model has a horizontal grid of 128 by 88 points, and 39 levels in the vertical coordinate. The model zonal and meridional winds are nudged to the European Centre for Medium-Range Weather Forecasts (ECMWF) ERA-Interim reanalysis [Dee et al., 2011], as described in Hourdin et al. [2015]. The nudging of the model is performed with a relaxation time of $48 \mathrm{~h}$ inside the zoom and $3 \mathrm{~h}$ outside the zoom. The nudging (or relaxation) of the model winds consists of adding a nonphysical term into the model equations to push the model to follow the reanalysis winds. Outside the zoom, the short relaxation time forces the model to follow closely the reanalysis winds. However, inside the zoom, the model is able to develop its own diurnal cycle and the features of the model physics and dynamics can fully develop (for example, the near-surface wind in Hourdin et al. [2015]). Sea surface temperature and surface ice and snow cover are also prescribed from ERA-Interim. The simulation period is the year 2006 for all our simulations and analysis, and the spin-up was performed over 1 year with nudged winds from ERA-Interim reanalysis.

Despite the global coverage of the model and the observations, we only assimilate observations in a reduced region of the globe. The selected assimilation region, defined as a rectangle with coordinates ranging from $70^{\circ} \mathrm{W}$ to $65^{\circ} \mathrm{E}$ in longitude and $0^{\circ} \mathrm{N}$ to $40^{\circ} \mathrm{N}$ in latitude, allows the system to assimilate both the aerosol AOD over Africa and the adjacent Atlantic Ocean (Figure 2).

\section{Results}

\subsection{Cost Function Decrease}

The data assimilation system successfully reduces the cost function $J(\mathbf{x})$ (equation (5)) to a value close to two thirds of the prior cost function value. In a consistent data assimilation system, the final value of $J(\mathbf{x})$ should be close to half the number of the observations [Talagrand, 1998]. In our case, with $\approx 709,000$ observations and with an initial value of the cost function equal to $\approx 650,000$, the system reaches the cost function value of $\approx 431,000$ in the analysis, which is somewhat larger than the ideal expected value of the cost function minimum.

This result could be explained by an imbalance between the prescribed $\mathbf{R}$ matrix and the covariance matrix of the innovation vector $\left(\mathbf{y}-H\left(\mathbf{x}^{b}\right)\right)$ and/or a systematic bias in the observation or in the observation operator 


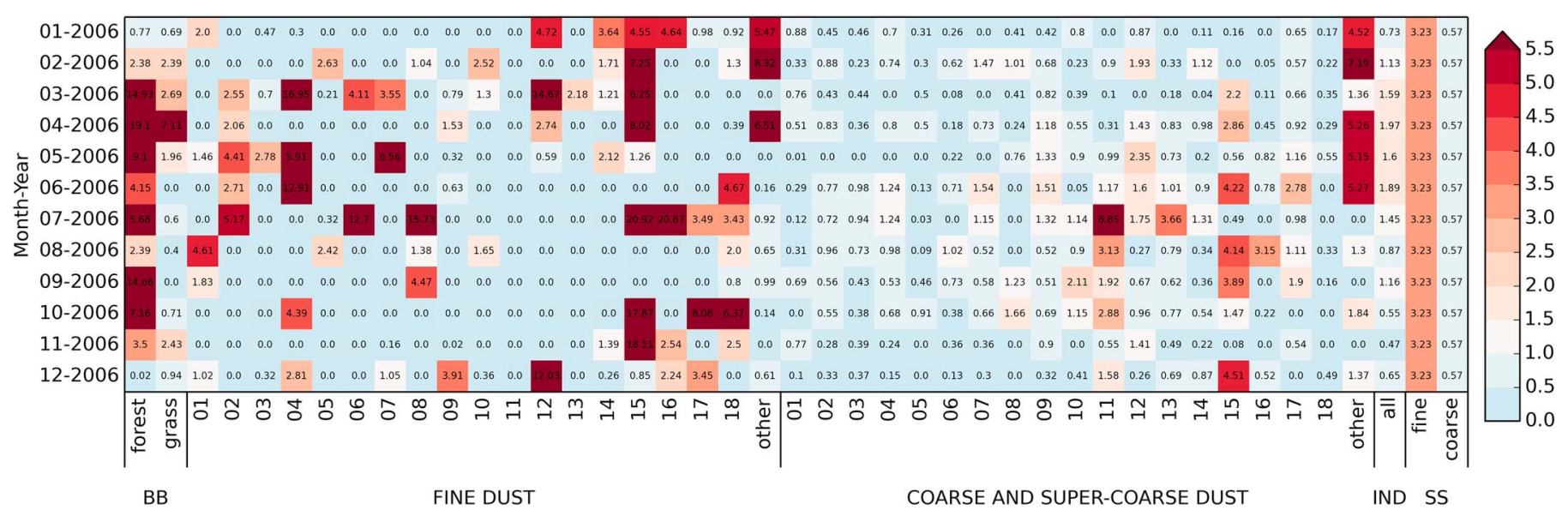

Figure 3. Analysis correction factors by subperiod (months) on the ordinate axis and subregion and category of emission on the abscissa axis. BB stands for biomass burning, IND for anthropogenic and fossil fuel emissions, and SS for sea salt emissions.

(model simulated AOD). In our case, the use of the Desroziers diagnostics to inflate $\mathbf{R}$ prevents the unbalance between the diagonal terms of the $\mathbf{R}$ matrix and the innovation vector, so we think that the difficulty to reach the theoretical minimum is more likely to be due to a combination of a bias in the observations, a bias in the observation operator, and the lack of off-diagonal terms in the $\mathbf{R}$ matrix.

It is interesting to note that the value of the cost function in the analysis is equal to $\approx 431,000$ when the full nonlinear model is used as observation operator, and $\approx 434,000$ when the linear approximation of the model is used instead. The small difference between the two values gives a qualitative confidence to the linear assumption of the observation operator, which is applied in the cost function minimization.

\subsection{Correction Factors}

Figure 3 shows the analysis control vector values $\left(\mathbf{x}^{a}\right)$, i.e., the optimal correction factors for the emission fluxes calculated with the data assimilation system. Given the information provided, the analysis is the most likely assignment for different aerosol types, subregions and subperiods. In Figure 3 the control vector elements are grouped by subregion and by category of emission in the abscissa and by subperiod (months) in the ordinate.

For fine mode dust, $84 \%$ of the analysis correction factors are less than unity, which means that most corrections reduce fine dust model emissions. For the fine mode emissions, $60 \%$ of the elements of the analysis $\mathbf{x}^{\mathbf{a}}$ equal zero, but some elements have relatively large values.

For the coarse and supercoarse mode dust, $77 \%$ of the analysis correction factors are less than unity, but unlike for the fine mode dust, the correction factors have a rather homogeneous distribution, with only $15 \%$ of the values close to zero and $8 \%$ of values greater than 2 . It seems to be contradictory to have, for the same subregion and subperiod, positive coarse and supercoarse dust emission and zero fine mode dust emissions. We will address this in section 4.

We can identify three groups of dust subregions in Figure 3. The eastern group includes subregions ranging from 1 to 8 , where coarse and supercoarse dust correction factors are mostly smaller than 1 and fine mode dust correction factors are predominantly either close to zero or larger than 2 (except in November). In particular, the transatlantic dust plume between March and September is generated by strongly emitting fine mode dust and decreasing coarse and supercoarse mode dust emissions. We distinguish a second group of subregions numbered between 9 and 14 where coarse and supercoarse dust correction factors are larger than the correction factors of the first group, and between May and November fine mode correction factors are small. A third group (composed by subregions numbered between 15 and 18) has a more heterogeneous behavior of dust correction factors than the two previous groups. This last group of correction factors is sensitive to the assimilated observations over the Arabian Peninsula and the Arabian Sea, while the other two previous groups are sensitive to assimilated AOD over the Sahara, the Sahel, and the Atlantic Ocean.

Forest biomass burning correction factors are greater than 2 between February and November, but these large correction factors do not strongly impact the analysis because the months with more forest biomass burning emission fluxes are December and January. On the other side, grass biomass burning correction factors in 
November, December, and between January and April do impact the analysis emissions. For sea salt emissions, Figure 3 shows an optimal correction factor of 3.2 for coarse mode sea salt emissions and 0.6 for fine mode emissions. This is associated with a strong posterior error anticorrelation (correlation factor of -0.9 ) between both elements in the control vector. As both fine and coarse mode sea salt correction factors share the same geographical emission region, the data assimilation system is unable to separate their relative contributions to the total $550 \mathrm{~nm} \mathrm{AOD}$, and thus, what is really optimized is the sum of both contributions to the total AOD.

\subsection{Comparison With MODIS}

The internal consistency of the inversion system can be qualitatively assessed by comparing the assimilated observations with the simulated AOD. A quantitative validation is given later in section 3.4.

Qualitatively, the prior model can reproduce the main features in AOD observed in the monthly averages (Figure 4). To some extent, the transported dust plume is well represented in the months when the dust emission is maximum, from June to August, and the model can produce dust levels in the Bodéle depression $\left(17^{\circ} \mathrm{N}\right.$, $18^{\circ} \mathrm{E}$ ) throughout the year. The local maximum of AOD in the Arabian Sea is also simulated. The westward transport of biomass burning aerosols to Central and South America in the boreal winter, as visible in the southern part of the panels, is noticeable.

The analysis efficiently reduces emissions in the northern part of the Sahara desert and achieves a better agreement with the assimilated AOD than the prior, as can be seen between March and August. A similar feature is found in the reduction of model emissions in the prior emission hot spot close to $10^{\circ} \mathrm{W}$ in longitude and $20^{\circ} \mathrm{N}$ in latitude and in the prior emission hot spot in the Iranian desert.

It appears that generally speaking the data assimilation system is more efficient in decreasing emissions than in increasing them. However, there are cases where the assimilation system can effectively increase emissions. For example, in the dust outbreak of 7-13 March (showed in Figure 4 as an AOD maximum close to $\left[10^{\circ} \mathrm{E}, 7^{\circ} \mathrm{N}\right.$ ] given the MODIS/Aqua sampling), it is clear that the assimilation system improves the fit with the observations by increasing emissions of fine mode dust in subregions 12 and 14. Even though this increase is not large enough to allow reproducing the AOD maximum, it represents an improvement with respect to the prior. Another example of the increase of AOD is for the month of July, when the analysis AOD over the Sahara is, in general, larger than the prior AOD.

The inversion system is designed to optimize not only dust emissions but rather all the emissions detailed in Figure 3. In particular, an increase of AOD of the analysis with respect to the prior can be seen over the Atlantic Ocean close to $35^{\circ} \mathrm{N}$, which is the least dust-influenced area of Figure 4 . These increase of AOD can be likely attributed to an increase in the local sea spray emissions or/and to an increase in emissions outside the assimilation region that are transported into the ocean.

\subsection{Comparison With AERONET}

To evaluate the performance of the analysis in comparison to the prior simulation, we select AERONET stations in the region of interest with a number of daily observations greater than half of the maximum number of observations in the year, i.e., stations with at least 182 daily AOD retrievals. This resulted in 13 stations for which the statistics against the two model simulations are presented in Table 1. We group the 13 stations into six groups according to their geographic locations, and for each group we select the one station with the longest record for which we show the time series of the simulated and observed AOD in Figure 5. The geographic location of AERONET sites is shown in Figure 1.

The overall statistics of the model performance against AERONET are summarized in Table 1. It should be noted that the AOD of the analysis is smaller than the AOD of the prior at all AERONET stations except llorin and La Parguera. The increase in AOD over the Caribbean station La Parguera is consistent with the larger fine mode dust fluxes of the analysis, as we will show in section 3.5. There is a clear improvement of the analysis simulation with respect to the prior one in two of our skill scores: the root-mean-square error (RMSE) is smaller for all the stations in the analysis run, and the Pearson correlation coefficient is also closer to unity in all the analysis simulations. The absolute value of the bias is reduced in five stations, and it is increased in other seven stations, and in general terms, the prior simulation is positively biased, while the analysis simulation is negatively biased.

Time series of simulated and observed AOD are shown in Figure 5. In general terms, the analysis simulation is capable of reducing a large number of AOD peaks of the prior simulations that are not observed by AERONET 


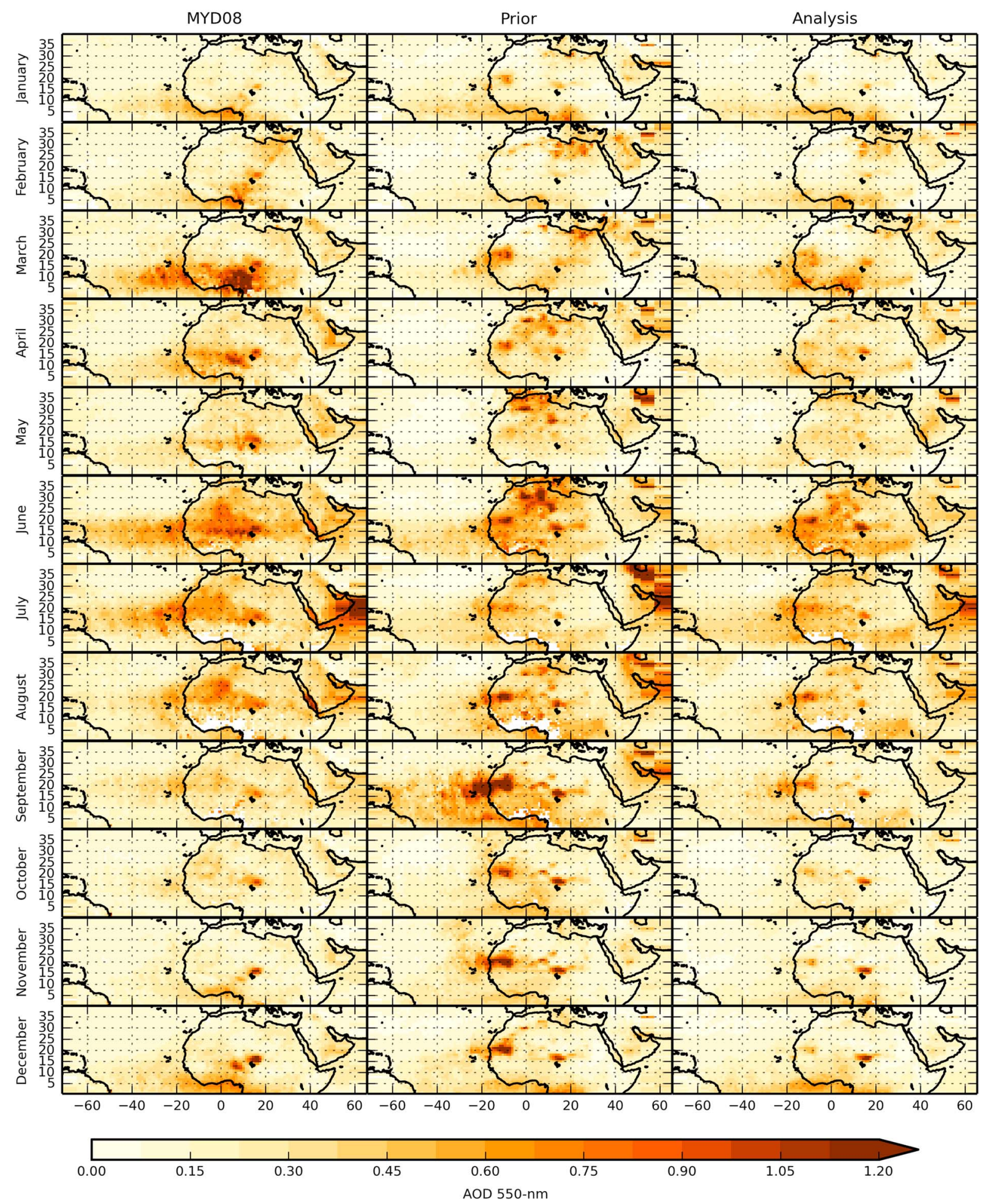

Figure 4. Monthly averages of $550 \mathrm{~nm}$ AOD from (left column) the MODIS/Aqua product, (middle column) the prior simulation, and (right column) the analysis simulation. The latitude is in the ordinate (in ${ }^{\circ} \mathrm{N}$ ) and the longitude in the abscissa $\left({ }^{\circ} \mathrm{E}\right)$. All the monthly averages were calculated by sampling only times when the MODIS product reports valid data. Complete lack of data for the month is depicted in white. 
Table 1. AERONET Sites Used in This Study and Statistics of the Simulated $550 \mathrm{~nm}$ AOD Against Daily AERONET Measurements ${ }^{\mathrm{a}}$

\begin{tabular}{|c|c|c|c|c|c|c|c|c|c|c|c|c|c|}
\hline \multirow[b]{2}{*}{ Station } & \multirow{2}{*}{$\begin{array}{l}\text { Latitude } \\
\qquad\left({ }^{\circ} \mathrm{N}\right)\end{array}$} & \multirow{2}{*}{$\begin{array}{l}\text { Longitude } \\
\qquad\left({ }^{\circ} \mathrm{E}\right)\end{array}$} & \multirow{2}{*}{$\begin{array}{c}\text { Elevation } \\
\text { (m above sea level) }\end{array}$} & \multirow[b]{2}{*}{ NObs. } & \multicolumn{3}{|c|}{ Mean } & \multicolumn{2}{|c|}{ Bias } & \multicolumn{2}{|c|}{ RMSE } & \multicolumn{2}{|c|}{$\rho$} \\
\hline & & & & & Obs & FG & AN & FG & AN & FG & AN & FG & AN \\
\hline Bahrain & 26.21 & 50.61 & 25 & 201 & 0.433 & 0.476 & 0.385 & 0.044 & -0.047 & 0.365 & 0.237 & 0.275 & 0.516 \\
\hline Blida & 36.51 & 2.88 & 230 & 195 & 0.258 & 0.321 & 0.244 & 0.063 & -0.013 & 0.356 & 0.188 & 0.59 & 0.647 \\
\hline Dhabi & 24.48 & 54.38 & 15 & 243 & 0.434 & 0.412 & 0.32 & -0.022 & -0.114 & 0.397 & 0.254 & 0.231 & 0.509 \\
\hline Dhadnah & 25.51 & 56.32 & 81 & 324 & 0.404 & 0.456 & 0.318 & 0.052 & -0.086 & 0.465 & 0.251 & 0.147 & 0.428 \\
\hline Forth Crete & 35.33 & 25.28 & 20 & 283 & 0.196 & 0.267 & 0.247 & 0.071 & 0.05 & 0.254 & 0.182 & 0.37 & 0.38 \\
\hline Granada & 37.16 & -3.6 & 680 & 276 & 0.177 & 0.216 & 0.186 & 0.039 & 0.009 & 0.246 & 0.138 & 0.653 & 0.719 \\
\hline Hamim & 22.97 & 54.3 & 209 & 263 & 0.314 & 0.349 & 0.273 & 0.035 & -0.041 & 0.264 & 0.168 & 0.449 & 0.675 \\
\hline Ilorin & 8.32 & 4.34 & 350 & 270 & 0.705 & 0.431 & 0.46 & -0.274 & -0.245 & 0.6 & 0.537 & 0.073 & 0.371 \\
\hline La Parguera & 17.97 & -67.05 & 12 & 251 & 0.148 & 0.147 & 0.155 & -0.001 & 0.008 & 0.148 & 0.103 & 0.28 & 0.38 \\
\hline Nes Ziona & 31.92 & 34.79 & 40 & 185 & 0.226 & 0.242 & 0.21 & 0.016 & -0.016 & 0.141 & 0.115 & 0.463 & 0.529 \\
\hline Santa Cruz Tenerife & 28.47 & -16.25 & 52 & 233 & 0.171 & 0.182 & 0.146 & 0.011 & -0.025 & 0.183 & 0.117 & 0.385 & 0.556 \\
\hline Sede Boker & 30.86 & 34.78 & 480 & 335 & 0.2 & 0.263 & 0.24 & 0.063 & 0.04 & 0.235 & 0.161 & 0.537 & 0.55 \\
\hline Solar Village & 24.91 & 46.40 & 764 & 335 & 0.372 & 0.373 & 0.367 & 0.001 & -0.005 & 0.273 & 0.252 & 0.393 & 0.497 \\
\hline
\end{tabular}

${ }^{\mathrm{a}} \mathrm{FG}$ stands for the prior simulation and AN for the analysis simulation. The statistics shown are the mean $550 \mathrm{~nm}$ AOD (Mean), the mean bias (Bias), the root-mean-square error (RMSE), and the Pearson correlation coefficient $(\rho)$.

(e.g., at the Granada site in April, Santa Cruz Tenerife site in October, or Solar Village site in September). In some cases the assimilation system increases the AOD toward the observations, as, for example, in March at the Ilorin site. Even though the bias in La Parguera site is increased in the analysis, the variability of the observed minus simulated AOD is improved by the analysis. Part of the errors in the analysis simulation can be attributed to the mismatch between AERONET and MODIS AOD, the assimilated product. For example, most of the model inaccuracy at llorin site (see Table 1) comes from the first 3 months of simulation, where the AERONET observations are considerably larger than both the model simulations and the MODIS/Aqua retrievals.

On monthly to seasonal temporal scales (not shown), the analysis performance is rather homogeneous, with calculated statistics similar to those of the whole year (Table 1) except for the bias and root-mean-square error (RMSE) for Granada and Blida stations (northern stations of Figure 1) where the improvement of the analysis is better in April, May, and June; in La Parguera, where there is a significant improvement of the bias and RMSE in September; and in Santa Cruz Tenerife where the bias and RMSE of the analysis are smaller than the prior simulation in September and October.

\subsection{Emission Fluxes}

Dust and biomass burning emission fluxes are summarized in Figure 6. The total amount of emitted dust in the prior simulation is $6690 \mathrm{Tg}$, of which $4095 \mathrm{Tg}$ are emitted in Northern Africa and $2595 \mathrm{Tg}$ in the rest of the domain (subregions 16, 17, and 18 of Figure 1). The total dust flux is reduced to $2897 \mathrm{Tg}$ in the analysis simulation (2179 Tg emitted in Northern Africa and $718 \mathrm{Tg}$ in the rest of the domain). The AEROCOM project [Huneeus et al., 2011] reports a plausible range of emissions between 400 and $2200 \mathrm{Tg} \mathrm{yr}^{-1}$ for North Africa and between 26 and $526 \mathrm{Tg} \mathrm{yr}^{-1}$ for Middle East. Although the analysis simulation is in the higher limit of this range, more recent studies suggest larger values of Saharan [Evan et al., 2014] $\left(4500 \pm 1500 \mathrm{Tg} \mathrm{yr}^{-1}\right)$ and global

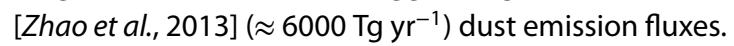

Dust emission of coarse and supercoarse mode bins are orders of magnitude larger than that for the fine mode, so the total amount of dust fluxes (in terms of mass) is controlled by the emission of the coarser particles. In the prior simulation, the flux of the coarse and supercoarse modes is $6662 \mathrm{Tg}$, while in the analysis this flux is $2866 \mathrm{Tg}$, with the reduction occurring for all months. The seasonal cycle of the coarser emissions is slightly different between the analysis and the prior simulations. Both of them show larger values in boreal summer than in winter, but the months of maximum emission are not the same: July, September, and March for the prior and June, August, and April for the analysis. In the spatial distribution, only two subregions (11 and 15) have more coarse and supercoarse dust emissions in the analysis simulation than in the prior one. The data assimilation system identifies large observational departures of AOD over subregion 18 (see Figure 4) 

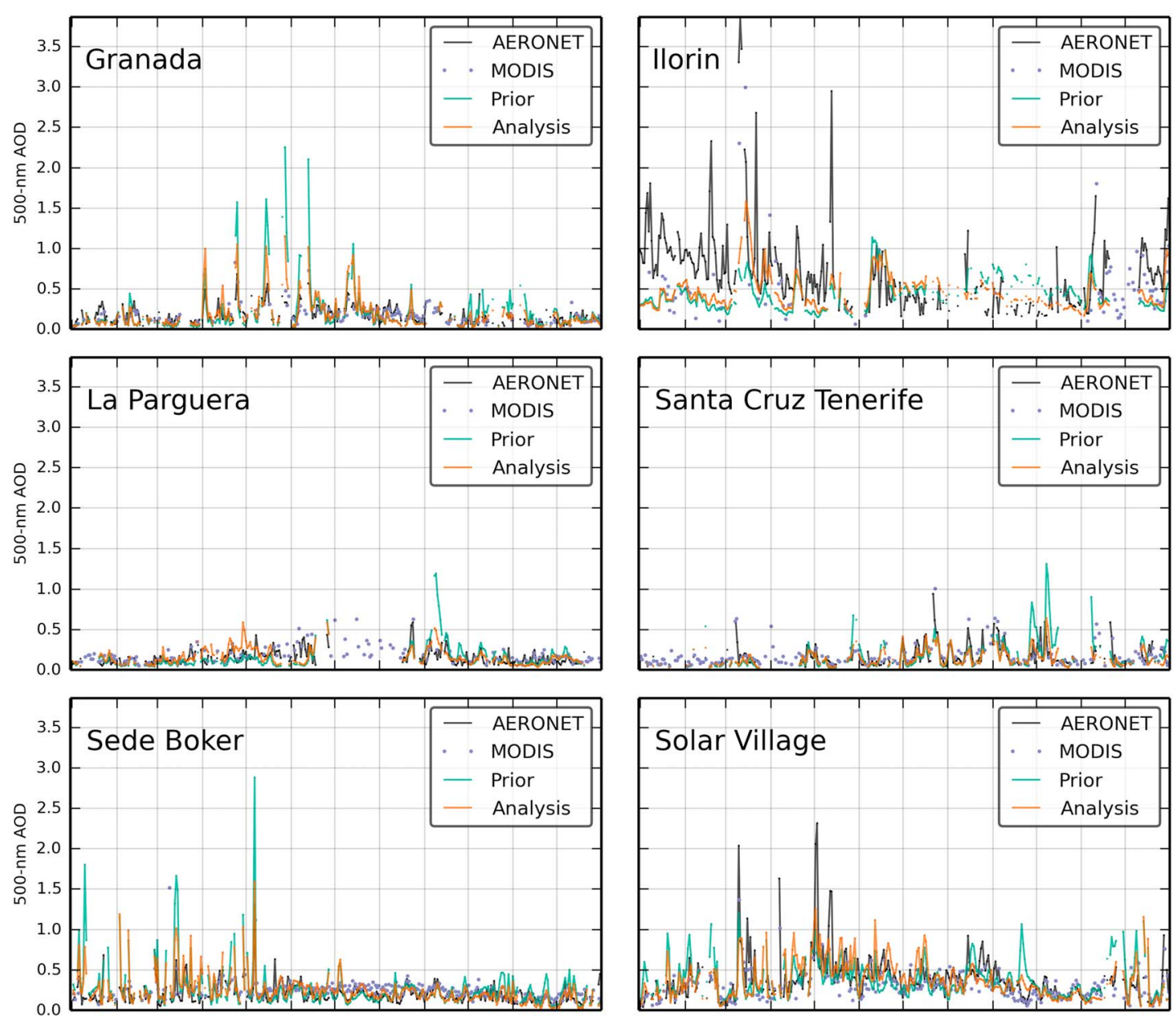

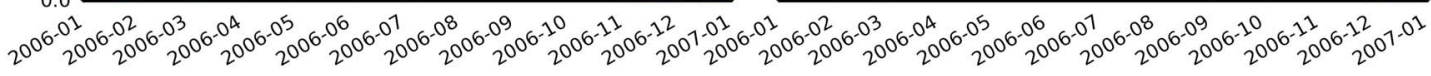

Date

Date

Figure 5. Model/AERONET comparison over six selected AERONET sites. Time series of AERONET $500 \mathrm{~nm}$ AOD (in black) and the two simulations with the prior simulation in green and the analysis simulation in orange. The name of each AERONET station is indicated on each panel. MODIS/Aqua retrievals are shown in purple. Simulated AOD is shown only for days when AERONET reports valid data.

and consequently produces a strong decrease of the analysis dust coarse mode emissions in this subregion (compared to prior emission).

On the contrary, fine mode dust emissions are larger in the analysis ( $30 \mathrm{Tg}$ ) than in the prior simulation $(27.6 \mathrm{Tg})$, despite the suppression of the fine mode dust emissions in several subregions of the analysis due to the null correction factor shown in Figure 3. Fine mode dust emissions are less important in terms of mass flux, but they are crucial for the 550-nm AOD field due to their larger mass extinction coefficient and longer residence time than the coarser dust. There is an important decrease of emissions between the prior and the analysis in subregions 3 and 11, but in both cases, an adjacent subregion ( 4 and 12, respectively) strongly increases emissions. The fine mode emission increase in July is due to values of the analysis correction factor larger than 3 in the eastern part of the region (subregions between 15 and 18), and it is also reflected in the large value of the overall emission flux for subregion 18.

In terms of flux uncertainty, we deliberately inflate the background error covariance matrix to obtain a prior dust emission flux uncertainty in the range of the dust flux spread reported in Huneeus et al. [2011]. The standard deviation of the prior dust flux error for the whole region is therefore close to $4140 \mathrm{Tg}$. For the analysis, this uncertainty measure is reduced to $31 \mathrm{Tg}$, which seems to be unrealistically low and will be discussed in section 4. 

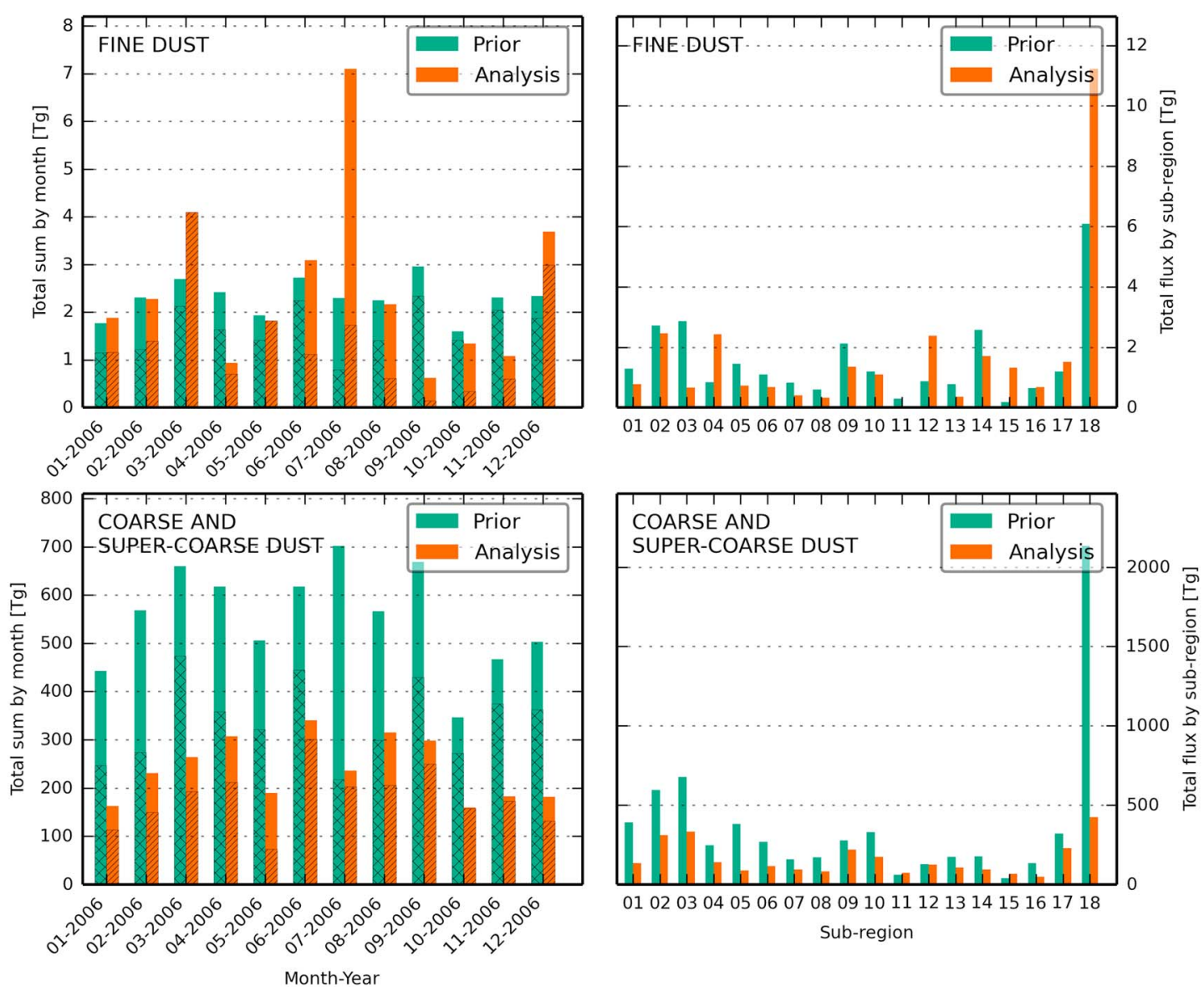

Figure 6. Dust emission fluxes in teragrams for the two model (prior and analysis) simulations. (top row) The emission fluxes for the fine mode; (bottom row) the coarse and supercoarse modes. (left column) Monthly sums of emissions; (right column) yearly 2006 emissions disaggregated by subregion. Total flux for Northern Africa (subregions 1 to 15) is indicated with a hatch pattern in Figure 6 (left column).

\section{Discussion}

The data assimilation system successfully modifies the dust fluxes in order to improve the agreement with the AOD observations, but there are pending challenges to be solved.

Over the Sahara, the shorter residence time of the coarse mode dust (relative to the fine mode) incites the assimilation system to preferably adjust the coarse mode dust emissions to get closer to the MODIS observations over land, while MODIS observations over the ocean are more relevant to the fine mode dust because of its longer residence time (Figure 4, left column). However, dust AOD over the ocean results from dust emitted over a large source area [e.g., Schepanski et al., 2007; Ginoux et al., 2012] in the Sahara and is subject to long-range transport and mixing along the air mass trajectory. The convergence of the fine mode dust emitted over the desert into a single dust plume over the Atlantic Ocean results in a difficult inversion problem for fine mode dust. In order to reduce the model AOD departures with respect to MODIS over the dust plume, the data assimilation system has various ways to adjust the fine mode dust emissions (Huneeus et al. [2016] showed how different emissions lead to a similar AOD behavior after long-range transport). In this context, the assimilation system prefers strongly decreasing the emissions for a large number of subregions and increasing the emissions for some subregions. It should be noticed that zero emissions for the fine mode dust cannot realistically coexist with nonzero emissions for the coarse and supercoarse mode dust.

In order to address the above, a higher quality total AOD and fine mode AOD product over land would be needed. The impact of including this product into assimilated observations has not been addressed yet, but we think that it could help the assimilation system to differentiate between fine and coarse mode dust emissions and hopefully avoid the problem of having zero dust fluxes in the fine mode. Preliminary tests indicate 
that assimilating MODIS fine mode AOD over ocean in addition to total AOD does not significantly improve neither the simulated comparison against AERONET nor the issue of having large number of subregions with zero fine mode emissions. For this reason, we think that fine mode AOD over land would be a more beneficial piece of information that is not currently available from MODIS.

A valuable product of the data assimilation is the quantification the analysis uncertainty. Our system underestimates the uncertainty of the analysis fluxes (see section 3.5). We have performed several sensitivity experiments (not shown) over the inflation parameters of $\mathbf{R}$ and $\mathbf{B}$ matrices (see section 2.3.3), concluding that neither the analysis control vector nor the $\mathbf{A}$ matrix is highly sensitive to these parameters. Off-diagonal terms in $\mathbf{R}$ are usually omitted, and the inflation of the $\mathbf{R}$ matrix should be enough to compensate the lack of these terms in most of the variational suboptimal assimilations systems [Rabier, 2005]. We would like to investigate if this holds for our inversion system, but more work is needed in order to properly define the off-diagonal terms of $\mathbf{R}$ and to quantify the impact of these terms in our analysis uncertainty.

Another question is whether there is a possible bias in the assimilated observations that should be corrected. MODIS AOD is retrieved from the Dark Target algorithm over ocean, and we use the retrievals either from the Deep Blue algorithm (for bright surfaces, as the desert) or from the Dark Target algorithm over land [Levy et al., 2013]. Therefore, a discontinuity in the AOD field is possible close to the coast. In Figure 4, this discontinuity can be noted mostly between the months of June and September, where the AOD close to the coast over land is smaller than that over the ocean at the same latitude. In this region, the AOD maximum is due to mineral dust emissions, which are only emitted over land and then transported westward. Over the desert, the Deep Blue algorithm systematically underestimates the AOD [Sayer et al., 2013], and the (assimilated) combined product could have discontinuities in regions where both Deep Blue and Dark Target algorithms report successful retrievals [Sayer et al., 2014]. This systematic bias between both MODIS AOD retrievals close to the coast may affect the analysis, providing contradictory information to the assimilation system. However, our tests indicate that assimilating data over the desert leads to better results than assimilating only the Dark Target product.

Besides the land/ocean bias described above, recent progress has been done to properly define and narrow the expected error (EE) estimates for the MODIS AOD products [Levy et al., 2013; Sayer et al., 2013]. In order to take advantage of these developments in a data assimilation framework, it would be necessary to include these EE in the $\mathbf{R}$ matrix. Preliminary tests show that the analysis performance decreases when the observational error is defined by a linear function of the MODIS AOD, and thus, we set a constant value for the observational error. However, these could change if the full EE derived in Sayer et al. [2013] is used (including the dependence of the error to the satellite viewing geometry). This EE has not been addressed yet in the source inversion system and would be interesting to implement it in the near future.

An additional source of error could come from the design of the data assimilation system. We assimilate daily AOD observations, but the control vector has only a monthly resolution. The variability of dust emissions at the scale of the subregions and subperiods is completely determined by the atmospheric and the dust production model, and errors at these scales negatively impact the inversion system, as they cannot be corrected by the assimilation system. Manual inspection of the model performance suggests that the issues discussed in the previous paragraphs are not necessarily associated with errors of submonthly scales of dust emission or transport, but further work should be done to quantify these errors.

\section{Conclusions}

We have estimated 1 year of dust fluxes over the Sahara and the Arabian Peninsula, by assimilating total AOD from MODIS in the aerosol transport model coupled to a dust production model and to the zoomed version of a general circulation model. Our adjoint-free assimilation system allows calculating correction factors for 18 subregions at a monthly resolution, and at an affordable computational cost over a 1 year period.

We present and apply an assimilation system that can perform natural aerosol source inversions over larger time windows and spatial coverage (e.g., by including the Arabian Peninsula) than previous regional studies with reasonable results.

In general terms, the analysis simulation is closer to the AOD observations than the prior simulation over the available AERONET stations. The data assimilation system is capable of improving spatial features observed in MODIS AOD with respect to the free-assimilation simulation. 
The total amount of dust emitted in the region is estimated to be approximately $2900 \mathrm{Tg}$ for the 2006 year, with most of the mass flux emitted by the coarse and supercoarse mode bins of the DPM (with diameters over $1 \mu \mathrm{m})$.

A large temporal window for the source inversion (of at least one decade) is needed in order to create a useful data set to be used by the aerosol and climate community and would help to have a more robust estimate of the annual dust emission over the region. The well-known interannual variability of dust sources is an interesting question to address, but before applying our framework to this problem, it is necessary to solve some critical issues detailed in the previous section.

The quality of the analysis partially depends on the quality of the atmospheric model. In particular, dust flux calculations improve when the model resolution increases. The source estimation approach presented in this work is applicable to other modeling systems (without needing an adjoint model) with increased horizontal resolution. We expect that the application of this inversion system in higher-resolution models will lead to a better and more accurate estimate of mineral dust fluxes.

This inversion system could be applied to tune parameters in the dust emission model instead of correction factors of the emissions, but this could be done in this framework only if perturbations of the parameters lead to linear (or approximatively linear) perturbations in the simulated observations. In this case, the assimilation system would need minimal modifications to attempt this task. More work is needed in order to identify and estimate plausible dust emission parameters in the DPM that can be efficiently adjusted through this method.

In the near future, we will try to assimilate more information than the total $550 \mathrm{~nm}$ AOD in order to improve our results in terms of fine mode emissions. To this end, a satellite retrieval with similar spatial and temporal coverage of MODIS total AOD but only for fine mode aerosols $550 \mathrm{~nm}$ AOD over the desert would be useful. Alternatively, it is also possible to modify the SPLA model to have more dust bins, but with cutoff diameters that are compatible with the small, medium, and large AOD retrievals from the MISR satellite, or with the small and coarse cutoff radii of the POLDER/PARASOL instrument.

\section{Acknowledgments}

The authors would like to thank the MODIS and AERONET teams for making the data available. MODIS AOD products are available at http://modis-atmos.gsfc.nasa.gov, and AERONET AOD is available at http://aeronet.gsfc.nasa.gov. Input soil data used in this study are available at http://www.lisa.univ-paris12.fr/mod/ data/index.php. The work was partially funded by the project OSIRIS from MEDDE/INSU and by the France-Chile ECOS project C14U01, and cofunded by the Copernicus Atmosphere Monitoring Service, implemented by the European Centre for Medium-Range Weather Forecasts (ECMWF) on behalf of the European Commission. Part of the work was done using computing time from the TGCC under the GENCI projects t2014012201 and t2015012201. Nicolás Huneeus acknowledges support from FONDAP 15110009 and FONDECYT 1150873.

\section{References}

Alfaro, S. C., and L. Gomes (2001), Modeling mineral aerosol production by wind erosion: Emission intensities and aerosol size distributions in source areas, J. Geophys. Res., 106(D16), 18,075-18,084, doi:10.1029/2000JD900339.

Ansmann, A., A. Petzold, K. Kandler, I. Tegen, M. Wendisch, D. Mueller, B. Weinzierl, T. Mueller, and J. Heintzenberg (2011), Saharan mineral dust experiments SAMUM-1 and SAMUM-2: What have we learned?, Tellus B, 63(4), 403-429, doi:10.1111/j.1600-0889.2011.00555.x.

Atkinson, J. D., B. J. Murray, M. T. Woodhouse, T. F. Whale, K. J. Baustian, K. S. Carslaw, S. Dobbie, D. O'Sullivan, and T. L. Malkin (2013), The importance of feldspar for ice nucleation by mineral dust in mixed-phase clouds, Nature, 498(7454), 355-358.

Benedetti, A., et al. (2009), Aerosol analysis and forecast in the European Centre for Medium-Range Weather Forecasts Integrated Forecast System: 2. Data assimilation, J. Geophys. Res., 114, D13205, doi:10.1029/2008JD011115.

Bocquet, M., L. Wu, and F. Chevallier (2011), Bayesian design of control space for optimal assimilation of observations. Part I: Consistent multiscale formalism, Q. J. R. Meteorol. Soc., 137(658), 1340-1356, doi:10.1002/qj.837.

Bocquet, M., et al. (2015), Data assimilation in atmospheric chemistry models: Current status and future prospects for coupled chemistry meteorology models, Atmos. Chem. Phys., 15(10), 5325-5358, doi:10.5194/acp-15-5325-2015.

Bousquet, P., et al. (2006), Contribution of anthropogenic and natural sources to atmospheric methane variability, Nature, 443(7110), 439-443, doi:10.1038/nature05132.

Bretl, S., P. Reutter, C. C. Raible, S. Ferrachat, C. S. Poberaj, L. E. Revell, and U. Lohmann (2015), The influence of absorbed solar radiation by Saharan dust on hurricane Genesis, J. Geophys. Res. Atmos., 120, 1902-1917, doi:10.1002/2014JD022441.

Cakmur, R. V., R. L. Miller, J. Perlwitz, I. V. Geogdzhayev, P. Ginoux, D. Koch, K. E. Kohfeld, I. Tegen, and C. S. Zender (2006), Constraining the magnitude of the global dust cycle by minimizing the difference between a model and observations, J. Geophys. Res., 111, D06207, doi:10.1029/2005JD005791.

Chevallier, F., et al. (2010), $\mathrm{CO}_{2}$ surface fluxes at grid point scale estimated from a global 21 year reanalysis of atmospheric measurements, J. Geophys. Res., 115, D21307, doi:10.1029/2010JD013887.

Dee, D. P. (2005), Bias and data assimilation, Q. J. R. Meteorol. Soc., 131(613), 3323-3343, doi:10.1256/qj.05.137.

Dee, D. P., et al. (2011), The ERA-Interim reanalysis: Configuration and performance of the data assimilation system, Q. J. R. Meteorol. Soc., 137(656), 553-597, doi:10.1002/qj.828.

Dentener, F. J., G. R. Carmichael, Y. Zhang, J. Lelieveld, and P. J. Crutzen (1996), Role of mineral aerosol as a reactive surface in the global troposphere, J. Geophys. Res., 101(D17), 22,869-22,889, doi:10.1029/96JD01818.

Desroziers, G., L. Berre, B. Chapnik, and P. Poli (2005), Diagnosis of observation, background and analysis-error statistics in observation space, Q. J. R. Meteorol. Soc., 131(613), 3385-3396, doi:10.1256/qj.05.108.

Dubovik, O., T. Lapyonok, Y. J. Kaufman, M. Chin, P. Ginoux, R. A. Kahn, and A. Sinyuk (2008), Retrieving global aerosol sources from satellites using inverse modeling, Atmos. Chem. Phys., 8(2), 209-250, doi:10.5194/acp-8-209-2008.

Evan, A. T., C. Flamant, S. Fiedler, and O. Doherty (2014), An analysis of aeolian dust in climate models, Geophys. Res. Lett., 41, 5996-6001, doi:10.1002/2014GL060545.

Fortems-Cheiney, A., F. Chevallier, I. Pison, P. Bousquet, M. Saunois, S. Szopa, C. Cressot, T. P. Kurosu, K. Chance, and A. Fried (2012), The formaldehyde budget as seen by a global-scale multi-constraint and multi-species inversion system, Atmos. Chem. Phys., 12(15), 6699-6721, doi:10.5194/acp-12-6699-2012. 
Ginoux, P., J. M. Prospero, T. E. Gill, N. C. Hsu, and M. Zhao (2012), Global-scale attribution of anthropogenic and natural dust sources and their emission rates based on MODIS Deep Blue aerosol products, Rev. Geophys., 50, RG3005, doi:10.1029/2012RG000388.

Goudie, A. S. (2014), Desert dust and human health disorders, Environ. Int., 63, 101-113, doi:10.1016/j.envint.2013.10.011.

Hakami, A., D. K. Henze, J. H. Seinfeld, T. Chai, Y. Tang, G. R. Carmichael, and A. Sandu (2005), Adjoint inverse modeling of black carbon during the Asian Pacific Regional Aerosol Characterization Experiment, J. Geophys. Res., 110, D14301, doi:10.1029/2004JD005671.

Haywood, J. M., R. P. Allan, I. Culverwell, T. Slingo, S. Milton, J. Edwards, and N. Clerbaux (2005), Can desert dust explain the outgoing longwave radiation anomaly over the Sahara during July 2003?, J. Geophys. Res., 110, D05105, doi:10.1029/2004JD005232.

Holben, B., et al. (1998), AERONET - A federated instrument network and data archive for aerosol characterization, Remote Sens. Environ., 66(1), 1-16, doi:10.1016/50034-4257(98)00031-5.

Hourdin, F., et al. (2013), LMDZ5B: The atmospheric component of the IPSL climate model with revisited parameterizations for clouds and convection, Clim. Dyn., 40(9-10), 2193-2222, doi:10.1007/s00382-012-1343-y.

Hourdin, F., M. Gueye, B. Diallo, J.-L. Dufresne, J. Escribano, L. Menut, B. Marticoréna, G. Siour, and F. Guichard (2015), Parameterization of convective transport in the boundary layer and its impact on the representation of the diurnal cycle of wind and dust emissions, Atmos. Chem. Phys., 15(12), 6775-6788, doi:10.5194/acp-15-6775-2015.

Huneeus, N., O. Boucher, and F. Chevallier (2009), Simplified aerosol modeling for variational data assimilation, Geosci. Model Dev., 2(2), 213-229, doi:10.5194/gmd-2-213-2009.

Huneeus, N., et al. (2011), Global dust model intercomparison in AeroCom phase I, Atmos. Chem. Phys., 11(15), 7781-7816, doi:10.5194/acp-11-7781-2011.

Huneeus, N., F. Chevallier, and O. Boucher (2012), Estimating aerosol emissions by assimilating observed aerosol optical depth in a global aerosol model, Atmos. Chem. Phys., 12(10), 4585-4606, doi:10.5194/acp-12-4585-2012.

Huneeus, N., O. Boucher, and F. Chevallier (2013), Atmospheric inversion of $\mathrm{SO}_{2}$ and primary aerosol emissions for the year 2010, Atmos. Chem. Phys., 13(13), 6555-6573, doi:10.5194/acp-13-6555-2013.

Huneeus, N., et al. (2016), Forecasting the northern African dust outbreak towards Europe in April 2011: A model intercomparison, Atmos. Chem. Phys., 16(8), 4967-4986, doi:10.5194/acp-16-4967-2016.

Jickells, T. D., et al. (2005), Global iron connections between desert dust, ocean biogeochemistry, and climate, Science, 308(5718), 67-71.

Journet, E., Y. Balkanski, and S. P. Harrison (2014), A new data set of soil mineralogy for dust-cycle modeling, Atmos. Chem. Phys., 14(8), 3801-3816, doi:10.5194/acp-14-3801-2014.

Kahn, R., D. Nelson, M. Garay, R. Levy, M. Bull, D. Diner, J. Martonchik, S. Paradise, E. Hansen, and L. Remer (2009), MISR aerosol product attributes and statistical comparisons with MODIS, IEEE Trans. Geosci. Remote Sens., 47(12), 4095-4114, doi:10.1 109/TGRS.2009.2023115.

Kaiser, J. W., et al. (2012), Biomass burning emissions estimated with a global fire assimilation system based on observed fire radiative power, Biogeosciences, 9(1), 527-554, doi:10.5194/bg-9-527-2012.

Knippertz, P., and J.-B. W. Stuut (2014), Mineral dust - A key player in the Earth system,Springer, Netherlands, doi:10.1007/978-94-017-8978-3.

Kok, J. F. (2011), A scaling theory for the size distribution of emitted dust aerosols suggests climate models underestimate the size of the global dust cycle, Proc. Natl. Acad. Sci. U.S.A., 108(3), 1016-1021.

Koren, I., Y. J. Kaufman, R. Washington, M. C. Todd, Y. Rudich, J. V. Martins, and D. Rosenfeld (2006), The Bodélé depression: A single spot in the Sahara that provides most of the mineral dust to the Amazon forest, Environ. Res. Lett., 1(1), 14005.

Lamarque, J.-F., et al. (2010), Historical (1850-2000) gridded anthropogenic and biomass burning emissions of reactive gases and aerosols: Methodology and application, Atmos. Chem. Phys., 10(15), 7017-7039, doi:10.5194/acp-10-7017-2010.

Lana, A., et al. (2011), An updated climatology of surface dimethylsulfide concentrations and emission fluxes in the global ocean, Global Biogeochem. Cycles, 25, GB1004, doi:10.1029/2010GB003850.

Levy, R. C., S. Mattoo, L. A. Munchak, L. A. Remer, A. M. Sayer, F. Patadia, and N. C. Hsu (2013), The Collection 6 MODIS aerosol products over land and ocean, Atmos. Meas. Tech., 6(11), 2989-3034, doi:10.5194/amt-6-2989-2013.

Lorenc, A. C., and O. Hammon (1988), Objective quality control of observations using Bayesian methods. Theory, and a practical implementation, Q. J. R. Meteorol. Soc., 114(480), 515-543, doi:10.1002/qj.49711448012.

Mahowald, N., S. Albani, J. F. Kok, S. Engelstaeder, R. Scanza, D. S. Ward, and M. G. Flanner (2014), The size distribution of desert dust aerosols and its impact on the Earth system, Aeolian Res., 15, 53-71, doi:10.1016/j.aeolia.2013.09.002.

Marticorena, B., and G. Bergametti (1995), Modeling the atmospheric dust cycle: 1. Design of a soil-derived dust emission scheme, J. Geophys. Res., 100(D8), 16,415-16,430, doi:10.1029/95JD00690.

Marticorena, B., G. Bergametti, B. Aumont, Y. Callot, C. N'DoumÃĬ, and M. Legrand (1997), Modeling the atmospheric dust cycle: 2. Simulation of Saharan dust sources, J. Geophys. Res., 102(D4), 4387-4404, doi:10.1029/96JD02964.

Menut, L., C. Pérez, K. Haustein, B. Bessagnet, C. Prigent, and S. Alfaro (2013), Impact of surface roughness and soil texture on mineral dust emission fluxes modeling, J. Geophys. Res. Atmos., 118, 6505-6520, doi:10.1002/jgrd.50313.

Nabat, P., F. Solmon, M. Mallet, J. F. Kok, and S. Somot (2012), Dust emission size distribution impact on aerosol budget and radiative forcing over the Mediterranean region: A regional climate model approach, Atmos. Chem. Phys., 12(21), 10,545-10,567, doi:10.5194/acp-12-10545-2012.

Nightingale, P. D., G. Malin, C. S. Law, A. J. Watson, P. S. Liss, M. I. Liddicoat, J. Boutin, and R. C. Upstill-Goddard (2000), In situ evaluation of air-sea gas exchange parameterizations using novel conservative and volatile tracers, Global Biogeochem. Cycles, 14(1), 373-387, doi:10.1029/1999GB900091.

Pannekoucke, O., L. Berre, and G. Desroziers (2008), Background-error correlation length-scale estimates and their sampling statistics, Q. J. R. Meteorol. Soc., 134(631), 497-508, doi:10.1002/qj.212.

Pedregosa, F., et al. (2011), Scikit-learn: Machine learning in Python, J. Mach. Learn. Res., 12, 2825-2830.

Peyridieu, S., et al. (2013), Atmos. Chem. Phys., 13(12), 6065-6082, doi:10.5194/acp-13-6065-2013.

Pilon, R., J.-Y. Grandpeix, and P. Heinrich (2015), Representation of transport and scavenging of trace particles in the Emanuel moist convection scheme, Q. J. R. Meteorol. Soc., 141(689), 1244-1258, doi:10.1002/qj.2431.

Rabier, F. (2005), Overview of global data assimilation developments in numerical weather-prediction centres, Q. J. R. Meteorol. Soc., 131(613), 3215-3233, doi:10.1256/qj.05.129.

Redelsperger, J.-L., C. D. Thorncroft, A. Diedhiou, T. Lebel, D. J. Parker, and J. Polcher (2006), African monsoon multidisciplinary analysis -An international research project and field campaign, Bull. Am. Meteorol. Soc., 87(12), 1739-1746, doi:10.1175/BAMS-87-12-1739.

Sayer, A. M., N. C. Hsu, C. Bettenhausen, and M.-J. Jeong (2013), Validation and uncertainty estimates for MODIS collection 6 "Deep Blue" aerosol data, J. Geophys. Res. Atmos., 118, 7864-7872, doi:10.1002/jgrd.50600.

Sayer, A. M., L. A. Munchak, N. C. Hsu, R. C. Levy, C. Bettenhausen, and M.-J. Jeong (2014), MODIS Collection 6 aerosol products: Comparison between Aqua's e-Deep Blue, Dark Target, and "merged" data sets, and usage recommendations, J. Geophys. Res. Atmos., 119, 13,965-13,989, doi:10.1002/2014JD022453. 
Schepanski, K., I. Tegen, B. Laurent, B. Heinold, and A. Macke (2007), A new Saharan dust source activation frequency map derived from MSG-SEVIRI IR-channels, Geophys. Res. Lett., 34, L18803, doi:10.1029/2007GL030168.

Schutgens, N., M. Nakata, and T. Nakajima (2012), Estimating aerosol emissions by assimilating remote sensing observations into a global transport model, Remote Sens., 4(11), 3528-3543, doi:10.3390/rs4113528.

Shao, Y., and H. Lu (2000), A simple expression for wind erosion threshold friction velocity, J. Geophys. Res., 105(D17), 22,437-22,443, doi:10.1029/2000JD900304.

Sow, M., S. C. Alfaro, and J. L. Rajot (2011), Comparison of the size-resolved dust emission fluxes measured over a sahelian source with the Dust Production Model (DPM) predictions, Atmos. Chem. Phys. Discuss., 11(4), 11,077-11,107, doi:10.5194/acpd-11-11077-2011.

Talagrand, O. (1998), A posteriori evaluation and verification of analysis and assimilation algorithms, in Workshop on Diagnosis of Data Assimilation Systems, 2-4 November 1998, pp. 17-28, ECMWF, Shinfield Park, Reading. [Available at http://www.ecmwf.int/en/elibrary/ 12547-posteriori-evaluation-and-verification-analysis-and-assimilation-algorithms.]

Tanré, D., F. M. Bréon, J. L. Deuzé, O. Dubovik, F. Ducos, P. François, P. Goloub, M. Herman, A. Lifermann, and F. Waquet (2011), Remote sensing of aerosols by using polarized, directional and spectral measurements within the A-train: The PARASOL mission, Atmos. Meas. Tech., 4(7), 1383-1395, doi:10.5194/amt-4-1383-2011.

van der Werf, G. R., J. T. Randerson, L. Giglio, G. J. Collatz, M. Mu, P. S. Kasibhatla, D. C. Morton, R. S. DeFries, Y. Jin, and T. T. van Leeuwen (2010), Global fire emissions and the contribution of deforestation, savanna, forest, agricultural, and peat fires (1997-2009), Atmos. Chem. Phys., 10(23), 11,707-11,735, doi:10.5194/acp-10-11707-2010.

Washington, R., M. C. Todd, S. Engelstaedter, S. Mbainayel, and F. Mitchell (2006), Dust and the low-level circulation over the Bodélé Depression, Chad: Observations from BoDEx 2005, J. Geophys. Res., 111, D03201, doi:10.1029/2005JD006502.

Washington, R., et al. (2012), Fennec-The Saharan climate system, CLIVAR Exch., 17(3), 31-33.

Woodward, S. (2001), Modeling the atmospheric life cycle and radiative impact of mineral dust in the Hadley Centre climate model, J. Geophys. Res., 106(D16), 18,155-18,166, doi:10.1029/2000JD900795.

Yumimoto, K., and T. Takemura (2013), The SPRINTARS version 3.80/4D-Var data assimilation system: Development and inversion experiments based on the observing system simulation experiment framework, Geosci. Model Dev., 6(6), 2005-2022, doi:10.5194/gmd-6-2005-2013.

Yumimoto, K., I. Uno, N. Sugimoto, A. Shimizu, Z. Liu, and D. M. Winker (2008), Adjoint inversion modeling of Asian dust emission using lidar observations, Atmos. Chem. Phys., 8(11), 2869-2884, doi:10.5194/acp-8-2869-2008.

Zender, C. S., H. Bian, and D. Newman (2003), Mineral Dust Entrainment and Deposition (DEAD) model: Description and 1990s dust climatology, J. Geophys. Res., 108(D14), 4416, doi:10.1029/2002JD002775.

Zhang, K., C. Zhao, H. Wan, Y. Qian, R. C. Easter, S. J. Ghan, K. Sakaguchi, and X. Liu (2016), Quantifying the impact of sub-grid surface wind variability on sea salt and dust emissions in CAM5, Geosci. Model Dev., 9(2), 607-632, doi:10.5194/gmd-9-607-2016.

Zhao, C., S. Chen, L. R. Leung, Y. Qian, J. F. Kok, R. A. Zaveri, and J. Huang (2013), Uncertainty in modeling dust mass balance and radiative forcing from size parameterization, Atmos. Chem. Phys., 13(21), 10,733-10,753, doi:10.5194/acp-13-10733-2013. 